\title{
The ileum positively regulates hepatic regeneration in rats $^{1}$
}

\author{
Aldo Cunha Medeiros', Ana Clara Batista Azevedo", Jéssica Mayara de Figueiredo Oséas ${ }^{\text {II }}$, Mariana Davim Ferreira Gomes ${ }^{\text {II }}$ \\ Fernanda Gurgel de Oliveira", Keyla Borges Ferreira Rocha ${ }^{\mathrm{III}}$, Ítalo Medeiros Azevedo ${ }^{\mathrm{IV}}$, Amália Cínthia Meneses Rêgo ${ }^{\mathrm{V}}$, \\ Marília Daniela Ferreira Carvalhov
}

IFull Professor, Chairman, Department of Surgery, Federal University of Rio Grande do Norte (UFRN), Natal-RN, Brazil. Conception, design, intellectual and scientific content of the study; analysis and interpretation of data; technical procedures; critical revision.

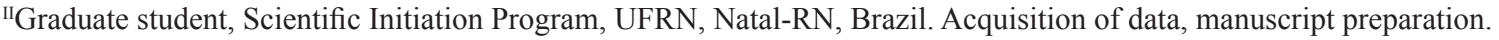

IIIAssociate Professor, Department of Pathology, UFRN, Natal-RN, Brazil. Acquisition and interpretation of data.

${ }^{\text {IV }}$ Master, Statistician, Department of Surgery, UFRN, Natal-RN, Brazil. Design of the study, interpretation of data, statistical analysis.

${ }^{\mathrm{v}}$ Fellow PhD degree, Postgraduate Program in Health Sciences, UFRN, Natal-RN, Brazil. Acquisition and interpretation of data.

\begin{abstract}
PURPOSE: To test the hypothesis that liver regeneration after partial hepatectomy can be influenced by the ileum.

METHODS: Eighteen Wistar rats were distributed into groups of six animals: 1 - ileum resection+ hepatectomy 2/3; 2 - hepatectomy 2/3, and 3 - sham. Anesthesia with ketamine and xylazine i.p., aseptic technique, analgesia with meperidine (10mg/kg s.c.). On day 6, serum ALT, AST, alkaline phosphatase (AP) and albumin were measured. Liver regeneration and hepatocyte mitosis were quantified. Statistical analysis with ANOVA and Tukey tests, with significance $\mathrm{p}<0.05$.

RESULTS: In group hepatectomy+ileal resection, ALT, AST and AP were 180.6 $\pm 24.9,58.6 \pm 3.1$ and $254.6 \pm 46.6$ respectively. They were significantly higher than in the hepatectomy group, whose values were $126.0 \pm 16.5,44.1 \pm 3.9$ and $163.5 \pm 8.6$, respectively ( $<<0.001$ ). Albumin levels were not significantly different among groups. Liver regeneration in hepatectomy group (94.17\%) was statistically higher $(\mathrm{p}<0.001)$ than in ileal resection+hepatectomy group $(55.96 \%)$. In the latter group the mitosis of hepatocytes were significantly less frequent than in the hepatectomy group.
\end{abstract}

CONCLUSION: The data confirm that the ileum positively influence on liver regeneration in rats undergoing hepatectomy. Key words: Hepatectomy. Liver. Ileum. Liver Regeneration. Rats. 


\section{Introduction}

Some analyzes have been conducted to investigate factors that regulate liver mass and regeneration like hormones ${ }^{1,2}$, and other factors ${ }^{3}$, but the nature of the signals have not been fully elucidated. Some mechanisms derived from intestine and portal circulation contribute to the regulation of the liver mass/body mass index. The role of the small intestine in regulating the hepatic regeneration after injury has been investigated, suggesting that intestine is the source of some humoral factors for regeneration after partial hepatectomy ${ }^{4-7}$. Some mechanisms derived from intestine and portal circulation may contribute to the regulation of the relative liver/body mass ${ }^{4,5}$. Other studies indicate that adaptation of small intestine post-resection, as well as ischemia/ reperfusion may influence regenerative liver response ${ }^{8,9}$. Huang et $a l .{ }^{10}$ demonstrated the factor named FXR which affects the absorption of bile acids which may regulate the liver mass and its recovery after injuries, supporting the role of the small intestine in the regulation of regeneration. Much is known about the signals and mechanisms of regeneration, both derived from the ligant/ receiver system, and from the whole body, including circulatory events and signals from other organs. Hepatocellular carcinoma study suggested that there may be more mechanisms contributing to the regulation of hepatocyte growth than those currently known ${ }^{11}$. Liver regeneration after partial $2 / 3$ hepatectomy in rats has been shown to be a useful model for the study of liver regeneration.

Based on these data, this study aims to test the hypothesis that liver regeneration after partial hepatectomy can be specifically regulated by ileum, intestinal segment that may be effective in the process. An experimental model of ileal resection examined the liver mass/body weight ratio, liver function tests and parameters of liver regeneration.

\section{Methods}

The experimental procedures performed in the study were done in accordance to the law $\mathrm{n}^{\mathrm{o}} 11.974 / 08$, Brazil, and approved by the Institutional Animal Care and Ethics Committee.

Eighteen Wistar rats were housed in individual polypropylene cages with cycles of $12 \mathrm{~h}$ light-dark, with ad libitum access to water and food (Labina-Purina ${ }^{\circledR}$ ), previously passing through a period of seven days acclimation in the laboratory.

One day before the operations, the animals were kept on liquid diet. Rats were distributed into 3 groups, each with 6 rats: group 1, hepatectomy+ ileonectomy; group 2, hepatectomy; group 3, sham. The rats were anesthetized with intraperitoneal (i.p.) injection of ketamine $(50 \mathrm{mg} / \mathrm{kg})$ and xylazine $(20 \mathrm{mg} / \mathrm{kg})$, and operated under aseptic technique. The postoperative pain was controlled with meperidine $10 \mathrm{mg} / \mathrm{kg}$ s.c., once every 12 hours.

The ileum resection $(30 \mathrm{~cm}$ long) was made from $2 \mathrm{~cm}$ proximal to the caecum. The intestinal continuity was restored by end-to-end anastomosis in a single running suture, using 6-0 polypropylene with a surgical microscope DFV (Sao Paulo, Brazil), up to 10x magnification. The sham operation consisted of laparotomy and manipulation of the ileum with atraumatic forceps; the abdominal wound was then sutured. The partial 2/3 hepatectomy consisted of resection of the median and left lobes. After the operations, animals received only water for the first 24 hours, followed by solid diet until euthanasia. The animals were weighed before surgery and every day until the $6^{\text {th }}$ observation day.

\section{Biochemical measures}

Serum from whole blood collected by cardiac puncture on the $6^{\text {th }}$ postoperative day was obtained by centrifugation at $1500 \mathrm{rpm}$ for 10 minutes and stored at $-30^{\circ} \mathrm{C}$ until dosages. Serum ALT, AST, alkaline phosphatase and albumin were measured in all animals.

\section{Calculation of liver regeneration}

Firstly we calculated the liver mass/body mass ratio (LMBMR). After the observation period the rats were weighed (B), the liver completely removed and weighed on a precision balance (A). The data obtained were expressed as the percentage ratio of A to B multiplied by 100 . The LMBMR was calculated by the formula:

\section{Liver mass \\ LMBMR= x 100 \\ Body mass}

The preoperative liver total weight was calculated using the average LMBMR of sham group at the time of euthanasia. Changes in LMBMR on animals of groups 1,2 and 3 were considered as degree of liver regeneration. The liver regeneration (LR) was calculated by the formula:

\section{LMBMReuthanasia - LMBMRpostop}

$\% \mathrm{LR}=$ x 100 


\section{Histology}

Euthanasia of animals was done by an overdose of anesthetic (thiopental $100 \mathrm{mg} / \mathrm{kg}$ i.p.). A sample of the right hepatic lobe was fixed in buffered formalin $10 \%$. Otherwise, tissue fractions were processed to be assessed for microscopic examination. Tissue slices were placed in cassettes and embedded in paraffin wax blocks. The blocks were then cut into $4 \mu \mathrm{m}$ sections using a microtome, mounted onto slides, dried and stained with haematoxylin and eosin. Slides were then viewed in a standard manner. Liver histology was performed to quantify the number of cells undergoing mitosis using BX50 microscope (Olympus, Tokyo, Japan). For each animal, five blades were made, and 10 microscopic fields were examined in each slide ( $\mathrm{x} 400$ magnification). Quantitation was obtained using video-assisted software (Image ProPlus 6.0, Cyber Media)

\section{Statistical analysis}

The data were analyzed using SPSS 18.0 (Chicago, IL, USA). To verify that the results obtained had statistically significant differences the following parametric tests were used: 1) Student's t - independent samples to compare between two groups, 2) analysis of variance (ANOVA) - to compare more than two groups, 3) Tukey test - used when the ANOVA showed significance, 4) Non-parametric Kruskal Wallis test - to check for differences between the three groups, when there was no homogeneity of variances, and 5) Dunnett test - when the Kruskal Wallis test showed significance; this test was used to determine in which groups the differences were statistically significant. For all tests the differences were significant when $\mathrm{p}<0.05$.

\section{Results}

All animals survived until the end of the observation period and showed no postoperative complications. The animals in groups hepatectomy+ileonectomy and hepatectomy showed progressive reduction in weight until the $6^{\text {th }}$ postoperative day, which was not observed in the sham group. In the hepatectomy+ileonectomy group the ALT, AST and AP were $180.6 \pm 24.9,58.6 \pm 3.1$ and $254.6 \pm 46.6$ respectively, significantly higher than in the hepatectomy group values $126.0 \pm 16.5,44.1 \pm 3.9$ and 163.5 \pm 8.6 , respectively $(\mathrm{p}<0.001)$. The albumin showed lower levels in the group undergoing hepatectomy+ileonectomy when compared with the other groups, but the difference was not significant $(\mathrm{p}=0.07)$. These data are summarized in Table 1.
TABLE 1 - Liver function tests.

\begin{tabular}{lcccc}
\hline Enzymes & $\begin{array}{c}\text { Hepatectomy+ } \\
\text { Ileonectomy }\end{array}$ & Hepatectomy & Sham & p-value \\
\hline $\begin{array}{l}\mathrm{ALT}^{3} \\
(\mathrm{U} / \mathrm{L})\end{array}$ & $180.6 \pm 24.9^{*}$ & $126.0 \pm 16.5^{*}$ & $44.5 \pm 4.4^{*}$ & $<0.001^{(1)}$ \\
$\begin{array}{l}\mathrm{AST} \\
(\mathrm{U} / \mathrm{L})\end{array}$ & $58 . \pm 3.1^{\S}$ & $44.1 \pm 3.9^{\S}$ & $49.1 \pm 3.5^{\S}$ & $<0.001^{(1)}$ \\
$\begin{array}{l}\text { Alkaline } \\
\text { phospha- } \\
\text { tase }\end{array}$ & $254 . \pm 46.6^{*}$ & $163.5 \pm 8.6^{\star}$ & $139.1 \pm 16.1^{\star}$ & $0.001^{2}$ \\
\hline $\begin{array}{l}\text { Albumin } \\
\text { (g/dL) }\end{array}$ & $5.4 \pm 2.5$ & & & \\
\hline
\end{tabular}

Mean \pm Standard deviation

1 - p-value (analysis of variance ANOVA)

2 - p-value Kruskal-Wallis test

3 - Values in the same row followed by the same symbol mean statistically significant difference by Tukey test

4 - Values in the same row followed by the same symbol mean statistically significant difference by Dunnett test

Liver regeneration of sham group rats was calculated. However, it showed an average 0.0. This was due to the fact that hepatic regeneration calculations were made considering the measures of the livers of animals from this group.

As we calculated liver mass/body mass ratio (LMBMR), using the livers of the sham group rats, it was possible to find a LMBMR average of 0.0318 . So, the weight of the liver of rats - in the same conditions as age, sex and race - represented $3.18 \%$ of their body weight.

Data in Table 2 show that the liver regeneration of hepatectomy group rats was statistically higher (94.17\%) than the group hepatectomy+ileonectomy $(55.96 \%)$.

TABLE 2 - Hepatic regeneration.

\begin{tabular}{c|c|c|c}
\hline \multirow{2}{*}{ Organ } & \multicolumn{2}{|c|}{ HEPATIC REGENERATION (\%) } & \multirow{2}{*}{ p-value $^{(1)}$} \\
\cline { 2 - 3 } & $\begin{array}{c}\text { Ileonectomy+ } \\
\text { hepatectomy }\end{array}$ & Hepatectomy & \\
\hline Liver & $55.96 \pm 12.41$ & $94.17 \pm 13.13$ & $<0.001$ \\
\hline
\end{tabular}

Mean \pm Standard deviation

1. $p$-value by the Student $t$ test for independent samples

Histological analysis revealed that in liver of animals undergoing hepatectomy+ileonectomy occurred a number of hepatocyte mitosis (75) significantly lower than in animals undergoing hepatectomy alone (154) as shown in Figure 1. Figure 2 shows liver cells undergoing mitosis in the blades B and B1 from hepatectomy group rats. 


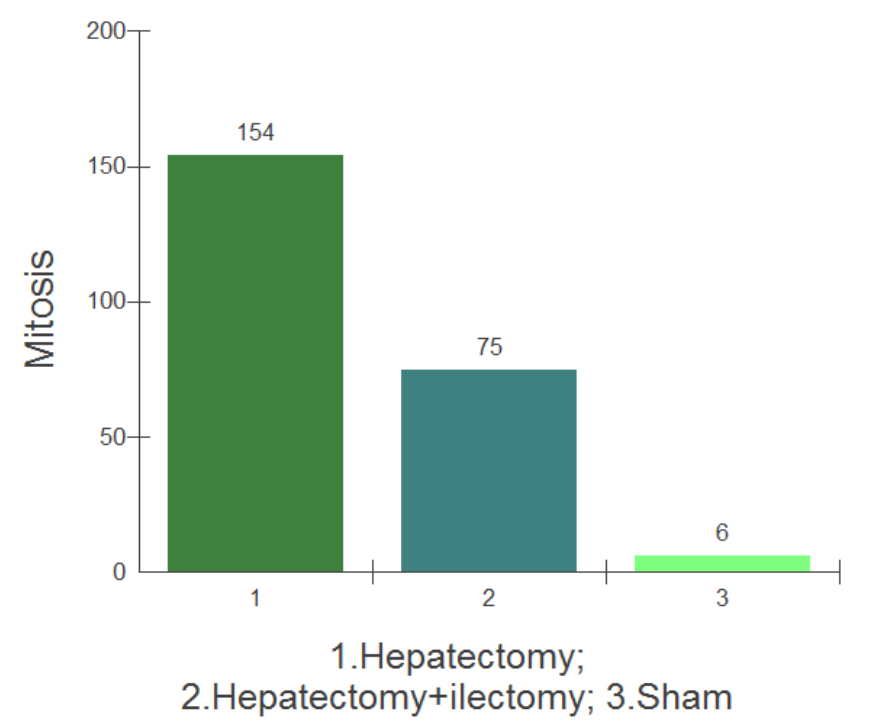

FIGURE 1 - Graph representing the number of mitosis seen in hepatocytes. $\mathrm{p}<0.015$ comparing groups $1,2,3$.
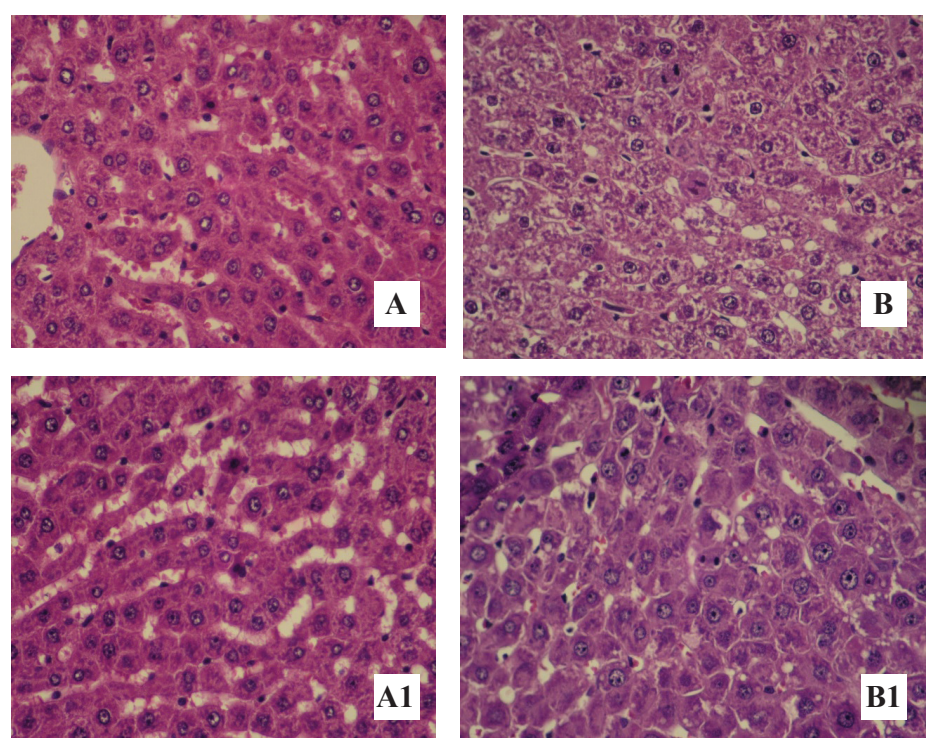

FIGURE 2 - Postoperative histological analysis. Liver sections from Wistar rats were stained with HE for the presence of mitosis. $\mathbf{A}$ and A1: microphotographs from hepatectomy + ileal resection rats demonstrated the presence of normal hepatocytes and rare mitosis. $\mathbf{B}$ and $\mathbf{B} 1$ : representative microphotographs from day 6 after hepatectomy rats showed several mitosis (arrows); magnification x400.

\section{Discussion}

In the present study we worked with the hypothesis that resection of the distal small bowel could interfere with liver regeneration after hepatectomy. Our data demonstrated that resection of ileum impaired liver regeneration after $70 \%$ hepatectomy. The ileonectomy resulted in reduced ability to regenerate remnant liver and consequent decrease in liver mass, featuring an attenuated proliferative response. These data imply that resection of the ileum, an organ that has great capacity for adaptation after resection, impairs liver regeneration at least the first week after surgery, when regeneration occurs intensively in rodents. These data also endorse an important role in the regulation of intestinal mucosa of liver regeneration. It is possible that the small bowel is a significant source of hepatotrophic factors that are present in portal blood perfusing the liver. The removal of $50 \%$ of the distal intestine may have reduced the gut hepatotrophic ability as an important factor in regeneration. Indeed, it has been shown that several factors are implicated in liver regeneration, some of them expressed in the small intestine, including epithelial growth factor, interleukin-6 (IL-6) and tumor necrosis factor ${ }^{12}$.

The experimental model of this work has been adequate and widely used, based on two important aspects. Firstly, the removal of resected liver tissue is not associated with severe hepatic necrosis. Second, due to the multilobular structure of rat liver, hepatectomy is "clean" and easy. Thus, the regeneration of residual lobes is soon mediated by processes in liver tissue. Necrosis or severe inflammation there has not been observed ${ }^{12}$.

It was previously demonstrated increased intestinal expression of transforming growth factor after intestinal resection in rodents ${ }^{13}$. Hepatic growth factor has been shown in the intestine remaining after ileal resection in rats $^{14}$. Concerning to IL-6, its serum levels were shown increased after 70\% ileum resection in rats, but without statistical significance ${ }^{15}$. These data reinforce the argument against the fact that resection of the ileum induces deficiency of these factors to slow liver regeneration. Another factor that may have contributed to the attenuation of liver regeneration in our study, after bowel resection, was the fact that the lack of the ileum implies lower supply of nutrients to the liver after extensive bowel resection. This nutritional problem has resulted in the reduction of gluconeogenic precursors from the intestine to the liver ${ }^{16}$.

It has been shown that rats initially lose weight, as occurred in the animals of this study, but become anabolic by the third postoperative day ${ }^{17}$. Was observed in our animals a reduction in the levels of albumin in the group undergoing hepatectomy+ileonectomy, with no significant difference compared with the other groups. Thus, we do not believe that nutritional changes could occur in our rats. They were initially normal and were observed for only six days. Assuming that serum albumin levels were not affected, nutrition could not interfere on our findings of liver regeneration. 
In several animal models it has been demonstrated that bacterial translocation to the mesenteric lymph nodes, liver and spleen is increased after intestinal resection ${ }^{18-20}$. Although in this study we have not studied bacterial translocation, it is speculated that the mechanism for this to occur is not yet known, but hardly is secondary to simple changes in intestinal permeability after ileal resection ${ }^{21}$. It was also shown that bacterial translocation occurs after major hepatic resection ${ }^{22}$. Endotoxins were shown to have a significant negative effect on liver regeneration after partial hepatectomy ${ }^{23}$. Thus, it is possible that the increase of endotoxins and bacteria into the portal blood, which has been demonstrated after intestinal and liver resection, could have affected liver regeneration.

The experimental model combining intestinal and liver resection is not new. Kahn et al. ${ }^{24}$ in 1990 reported an increase in liver regenerative response when a ileocolectomy was performed in pigs. The authors concluded that the proximal colon can be a source of regenerating liver inhibitory factor, unlike what was observed after ileum resection. Despite the colon resection was not performed in the present study, we intend to use this model in the near future in this research line. In other studies, impaired liver regeneration after bowel resection has been demonstrated ${ }^{25-28}$, confirming the findings of the present study.

\section{Conclusion}

The data obtained showed that the ileum resection negatively influences the liver regeneration in rats undergoing hepatectomy.

\section{References}

1. Biondo-Simões ML, Erdmann TR, Ioshii SO, Matias JE, Calixto HL, Schebelski DJ. The influence of estrogen on liver regeneration: an experimental study in rats. Acta Cir Bras. 2009;24:3-6.

2. Biondo-Simões ML, Castro GR, Montibeller GR, Sadowski JA, BiondoSimões R. The influence of hypothyroidism on liver regeneration: an experimental study in rats. Acta Cir Bras. 2007;22(Suppl 1):52-6.

3. Michalopoulos GK. Liver regeneration. J Cell Physiol. 2007;213:286-300.

4. Nelson LA, O’Brien DP, Kemp CJ, Williams JL, Dunke-Jacobs E, Erwin CR, Warner BW. Intestinal and hepatic response to combined partial hepatectomy and small bowel resection in mice. Am J Surg. 2002; 183:435-40.

5. Xu CP, Liu J, Liu JC, Han DW, Zhang Y, Zhao YC. Dynamic changes and mechanism of intestinal endotoxemia in partially hepatectomized rats. World J Gastroenterol. 2007;13:3592-7.

6. Takada N, Ogita K, Taguchi T, Masumoto K, Suita S. The effect of a valine-rich diet on intestinal adaptation to massive small bowel resection in the rat. Transplant Proc. 2006;38:1830-5.

7. Jeschke MG, Bolder U, Finnerty CC, Przkora R, Müller U, Maihöfer R, Thompson JC, Wolf SE, Herndon DN. The effect of hepatocyte growth factor on gut mucosal apoptosis and proliferation, and cellular mediators after severe trauma. Surgery. 2005;138:482-9.
8. Iyer KR, Horslen S, Torres C, Vanderhoof JA, Langnas AN. Functional liver recovery parallels autologous gut salvage in short bowel syndrome. J Pediatr Surg. 2004;39:340-4.

9. Atici AE, Kaya Y, Coskun T, Aral E, Var A. Intestinal ischemiareperfusion impairs liver regeneration after partial hepatectomy in rats. Hepatogastroenterology. 2003;50:661-5.

10. Huang W, Ma K, Zhang J, Qatanani M, Cuvillier J, Liu J, Dong B, Huang X, Moore DD. Nuclear receptor-dependent bile acid signaling is required for normal liver regeneration. Science. 2006;312:233-6.

11. Keng VW, Villanueva A, Chiang DY, Dupuy AJ, Ryan BJ, Matise I, Silverstein KA, Sarver A, Starr TK, Akagi K, Tessarollo L, Collier LS, Powers S, Lowe SW, Jenkins NA, Copeland NG, Llovet JM, Largaespada DA. A conditional transposon-based insertional mutagenesis screen for genes associated with mouse hepatocellular carcinoma. Nature Biotechnol. 2009;27:264-74.

12. Fausto N. Liver regeneration. J Hepatol. 2000;32:19-31.

13. Falcone Jr RA, Stern LE, Kemp CJ, Erwin CR, Warner BW. Intestinal adaptation occurs independent of transforming growth factor-alpha. J Pediatr Surg. 2000;35:365-70.

14. Taylor R, Beveridge D, Nakamura T, Fuller P. Hepatocyte growth factor gene expression after massive small bowel resection: lack of stimulation in lung and liver. Exp Clin Endocrinol Diabetes. 1995; 103:58-62.

15. Lo HC, Tsai FA, Lin SC, Wang HF. Systemic and local secretions of cytokines and nitric oxide in massive bowel resected rats with or without small bowel segment reversal. Cytokine. 2001;14:112-20.

16. Souba WW, Roughneen PT, Goldwater DL, Reed RL, Rowlands BJ. Effects of enterectomy on postoperative visceral organ glucose exchange. J Parenter Enteral Nutr. 1989;13:128-31.

17. Helmrath MA, Erwin CR, Warner BW. A defective EGF-receptor in waved-2 mice attenuates intestinal adaptation. J Surg Res. 1997;69:76-80.

18. Schimpl G, Feierl G, Linni K, Uitz C, Ozbey H, Höllwarth ME. Bacterial translocation in shortbowel syndrome in rats. Eur J Pediatr Surg. 1999;9:224-7.

19. Eizaguirre I, Aldazabal P, Barrena MJ, Garcia-Arenzana JM, Alcorta M, Ariz C, Candelas S, Tovar JA. Bacterial translocation is favored by the preservation of the ileocecal valve in experimental short bowel with total parenteral nutrition. Eur J Pediatr Surg. 1999;9:220-3.

20. Eizaguirre I, Aldazabal P, Barrena MJ, Garcia-Arenzana JM, Ariz C, Candelas S, Tovar JA. Effect of growth hormone, epidermal growth factor, and insulin on bacterial translocation in experimental short bowel syndrome. J Pediatr Surg. 2000;35:692-5.

21. O'Brien DP, Nelson LA, Stern LE, Williams JL, Kemp CJ, Wang Q, Tso P, Erwin CR, Hasselgren PO, Warner BW. Epithelial permeability. Epithelial permeability is not increased in rats following small bowel resection. J Surg Res. 2001;97:65-70.

22. Wang XD, Parsson H, Andersson R, Soltesz V, Johansson K, Bengmark S. Bacterial translocation, intestinal ultrastructure and cell membrane permeability early after major liver resection in the rat. Br J Surg. 1994;81:579-84.

23. Mochida S, Ogata I, Hirata K. Provocation of massive hepatic necrosis by endotoxin after partial hepatectomy in rats. Gastroenterology. 1990;99:771-7.

24. Kahn D, von Sommoggy S, Hickman R. Ileocolectomy enhances the regenerative response after partial hepatectomy in the pig. S Afr J Surg. 1990;28:11-3.

25. Miyazaki M, Kohda S, Itoh H. Inhibition of hepatic regeneration after $70 \%$ partial hepatectomy by simultaneous resection of the bowel in rats. Eur Surg Res. 1995;27:396-405.

26. Fisher B, Szuch P, Levine M. The intestine as a source of a portal blood factor responsible for liver regeneration. Surg Gynecol Obstet. $1973 ; 137: 210-4$. 
27. Medeiros AC, Brígido AR, Silva SM, Brito VR, Rocha KB, Oliveira $\mathrm{CN}$. The ileum as a determinant organ of the functional liver cell mass in rats. Acta Cir Bras. 2013;28:210-5.

28. Carvalho MD, Araújo-Filho I, Azevedo IM, Rêgo AC, Medeiros AC. Metabolic and hematologic consequences of colectomy associated to hepatectomy in rats. Acta Cir Bras. 2011;26:503-7.

\section{Correspondence:}

Aldo Cunha Medeiros

Avenida Nilo Peçanha, 620

59012-300 Natal - RN Brasil

Tel.: (55 84)3342-9773

aldo@ufrnet.br

Received: Oct 17, 2013

Review: Dec 18, 2013

Accepted: Jan 20, 2014

Conflict of interest: none

Financial source: National Council of Scientific and Technological Development (CNPq)

${ }^{1}$ Research performed at Nucleous of Experimental Surgery, Federal University of Rio Grande do Norte (UFRN), Natal-RN, Brazil. 